\title{
Diurnal Variation of Early Springtime Vertical Wind over the Tufan Dada Mountain Range of Far-Western Nepal
}

\author{
Ram P. Regmi \\ National Atmospheric Resource and Environmental Research Laboratory (NARERL) \\ Central Department of Physics, Tribhuvan University, Kirtipur, Kathmandu, Nepal. \\ ${ }^{*}$ Correspondence to: ram.p.regmi@gmail.com
}

\begin{abstract}
Early springtime diurnal variation of vertical wind over the $60 \mathrm{~km}$ long Tufan Danda mountain range located in the Far-Western Nepal has been numerically simulated with the application of WRF modeling system. Temporal and spatial distribution of vertical wind over the mountain range has been discussed up to tropospheric height. The study reveals that strong vertical wind gradient prevails throughout the troposphere of the area. The mountain wave excitations from the western edge of the mountain range appear to be propagated beyond the eastern edge of the mountain range enhancing regular bands of up-and downdrafts. The up- and downdrafts may extend beyond the tropospheric height during the late afternoon time in fair weather situations. The speed of the up-and downdrafts over the Tufan Dada may reach more than $180 \mathrm{~cm} \mathrm{~s}^{-1}$ and $200 \mathrm{~cm} \mathrm{~s}^{-1}$, respectively. High speed and great vertical extension of vertical wind over the area can significantly contribute in coupling the upper and lower atmospheric air masses and hence exchange of constituents. Tufan Danda mountain range could be one of the suitable site to monitor exchange of upper and lower atmospheric constituents.
\end{abstract}

Keywords: Atmospheric modeling, vertical velocity, atmospheric coupling, complex terrain, Tufan Danda.

\section{Introduction}

Importance of vertical air motion in understanding the dynamics of the atmosphere and their implications for several meteorological processes such as genesis of clouds, precipitation growth, convection, wave generation, and transport of mass, momentum and energy in the upper troposphere have been extensively discussed by several researchers [Uma and Rao, 2009; Ecklund, 1982; Nastrom and VanZandt, 1994; Yamamoto et al., 2007]. The vertical wind variability has been found significantly correlated with the wind speed and wind shear. The variability in the vertical wind can be interpreted as a measure of gravity wave activity [Eukland et al., 1981; Eukland et al.,1982]. Furthermore, the variability in the vertical air motion and its scale are largely affected by the presence of gravity waves, weather disturbances and large-scale general circulation [Wheeler et al., 2000; Piani and Durran, 2001; Uma and Rao, 2009].

Unlike the horizontal winds, vertical wind motions are generally very small in quantities and hence accurate measurements of vertical wind speeds are often difficult. Until the introduction of advance wind profiling technology, vertical winds were estimated from other meteorological parameters such as horizontal winds, temperature and pressure measurements. Common methods to estimate 
vertical motions include kinematic, adiabatic, trajectory and numerical methods. At present, vertical motions are directly measured with high spatial and temporal resolutions [Gageetal., 1991, Uma and Rao, 2009] by deploying all weather equipment like very high frequency (VHF) radar wind profiler. The echoes thus received due to the refractivity fluctuations caused by turbulence are analyzed to obtained vertical wind motions. [Röttger, 1980; Gage, 1990; Gage et al., 1991; Cifelli and Rutledge, 1994; Jagannadha Rao et al., 2003; Dhaka et al., 2002]. However, Nepal is yet to develop its remote sensing facility and a good network of surface observatories. In such situations, numerical methods could be the only way to understand the local and regional scale vertical transport processes and their spatial and temporal distributions over the area of interest.

There have been some significant efforts to understand atmospheric transport processes over the Nepal Himalaya [e.g., Kitada and Regmi, 2003; Regmi et al., 2003; Panday and Prinn, 2009; Shrestha et al., 2010; Shrestha and Barros, 2010; Brun et al., 2011]. Himalayas and its immediate surroundings hold extreme topographic complexities and hence a myriad of extraordinary meteorological phenomena can be associated with them. As part of the ongoing research on characterization of meteorological flows over the middle hills of Nepal Himalayas, several areas including the Far-Western region have been studied. The study has revealed diverse nature of flow fields [e.g., Regmi and Maharjan, 2013; Maharjan, 2014a; Maharjan and Regmi, 2014; Regmi, 2014; Regmi, 2013a; Regmi, 2013b; Maharjan and Regmi, 2013; Maharjan, 2014b; Regmi, 2014; Acharya et al., 2014].
The middle hills of the Far-Western region of Nepal hold distinctly different meteorological flow characteristics compared to other parts of the country so far studied [Regmi and Maharjan, 2014]. Present study area is located in the complex terrain of FarWestern region bestowed with majestic natural beauties. The bird-eye view of area is shown in Figure 1. This is the region where complex interactions of regional air mass circulations occur leading to a strong upslope wind towards the high Himalayas during the daytime whereas during the nighttime the downslope wind from the region may penetrate deep into the Ganga Plain beyond the boarder. Tufan Danda, as its name refers, is considered to be one of the mountain range where strong prevails most of the time during the dry season. The mountain chain extends for about 60 kilometer with rugged hills with an average height of $2 \mathrm{~km}$ above the mean sea level (AMSL) in the westeast direction.

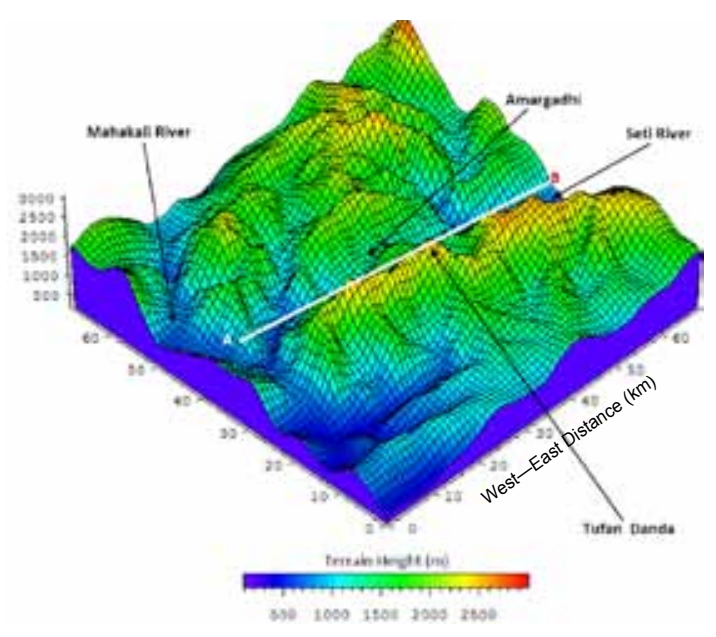

Figure 1. Three-Dimensional topographic view of Tufan danda range and its surroundings in FarWestern Nepal. Along the line $\mathrm{A}-\mathrm{B}$ cross sectional, distribution of vertical winds are discussed. 
In this paper we will discuss the early springtime vertical wind variability over the Tufan Danda as revealed by numerical simulation of regional scale local flows.

\section{Methodology}

The third generation Weather Research and Forecasting WRF Modeling System [Skamarock et al., 2008] with core ARW has been applied to compute the diurnal variability of vertical velocity over the Tufan Danda range. It is a fully compressible and non-hydrostatic model with a run-time hydrostatic option. The model utilizes a terrain-following hydrostatic pressure coordinate system, Arakawa C-grid staggering and Runge-Kutta 2nd and 3rd order time integration schemes, and 2nd to 6th order advection schemes in both the horizontal and vertical, thus, making highly suitable to perform simulation over a highly complex terrain.

A triply nested two-way interacting mesh of horizontal grid sizes $9,3,1 \mathrm{~km}$ for coarse, fine, and finest domains, respectively, with 35 vertical levels was adopted for present calculation. Coarse and fine domains consists $(52 \times 52)$ grid points where as finest contains $(70 \times 70)$ grid points. The centers of all the domains were set at Amargadi of Dadeldhura district $\left(29.31^{\circ} \mathrm{N}, 80.59^{\circ} \mathrm{E}\right)$ WRF offers a range of options for the parameterizations of sub-grid-scale processes. However, for this calculations we used the following physics options and schemes: WSM 3-class simple ice, Kain-Fritsch (for coarse domain only), Unified NOAH land-surface, YSU Planetary Boundary Layer, RRTM long wave, and Dhudhia short wave etc. The model was initialized with 10X10 horizontal resolution 6 hourly meteorological data from National Centers for Environmental Prediction (NCEP) and the 24 categories land use and 30 second terrain elevation data by United States Geological Survey (USGS).

The WRF model is initialized at 0000 UTC of a given day and is run for 48 simulated hours, storing the output every hour. The first day of the simulation has been discarded as a spin up of the model, and the values for the following 24 hours are retained for inspections. Following the same procedure the simulation results of continuous 168 hours (01 March 2014 to 8 March 2014) were gathered for study. The output interval was set for every 15 minutes

\section{Results}

After careful examinations of 168 hours simulation results, we came to the conclusions that the 02 March 2014 may be considered as a representative day for the early spring season under fair weather situations. The vertical extensions and temporal variations of vertical motion of air mass over the Tufan Dada mountain range can be conveniently assessed with the help of cross-sectional plots of vertical wind speed and potential temperature along the Tufan Dada ridge, i.e., along the line $\mathrm{A}-\mathrm{B}$ (see Figure 1 for the line). Figure 2 shows the diurnal variation of the vertical winds superimposed with potential temperature for every two hours intervals for the day of 02 March 2014 up to the height of troposphere, i.e., $12 \mathrm{~km}$ AMSL.

During the morning hours (see Figure 2a), the troposphere of the western lowland valley area possesses negligible up- and downdrafts with some scattered near surface and upper troposphere. The distribution and shape 

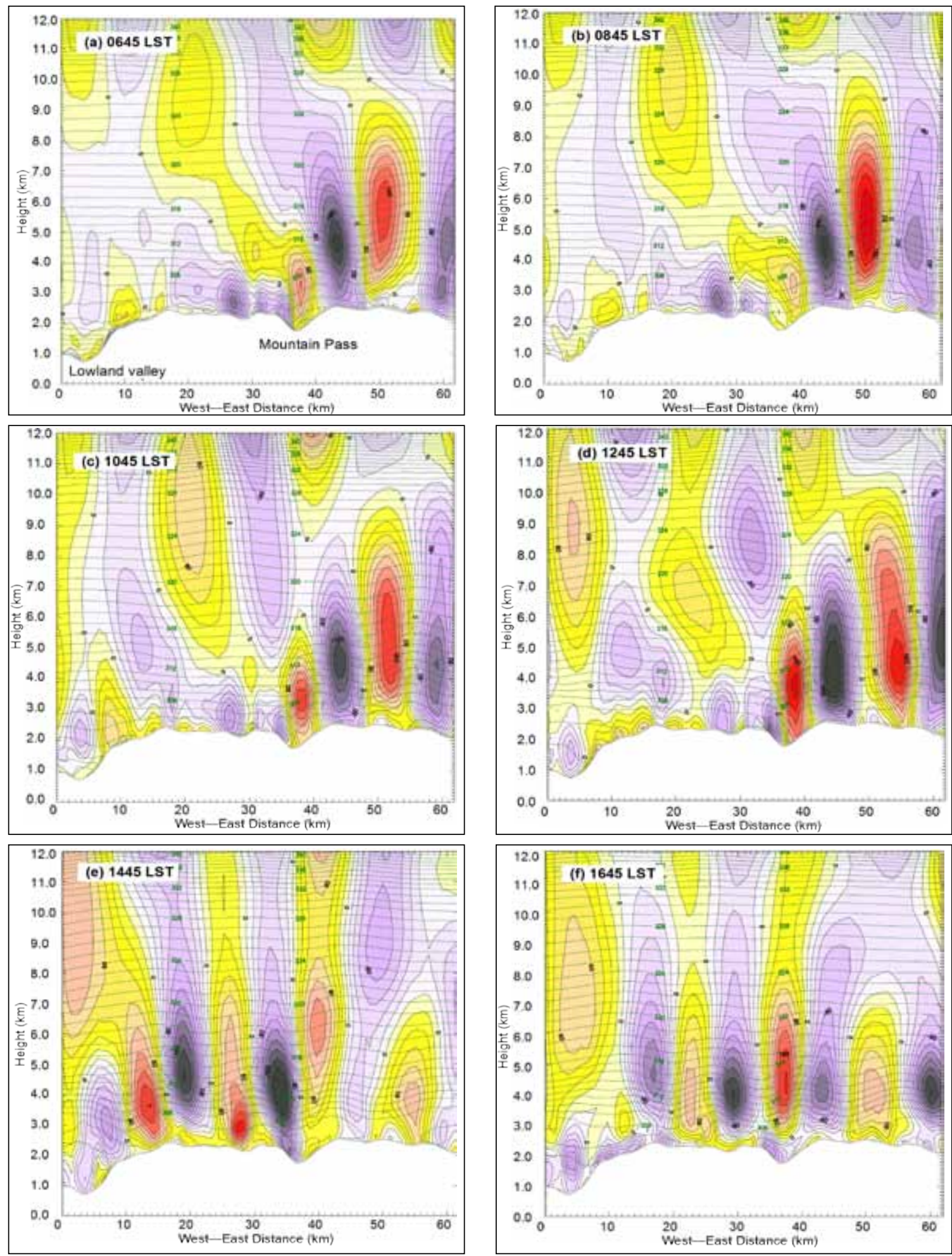

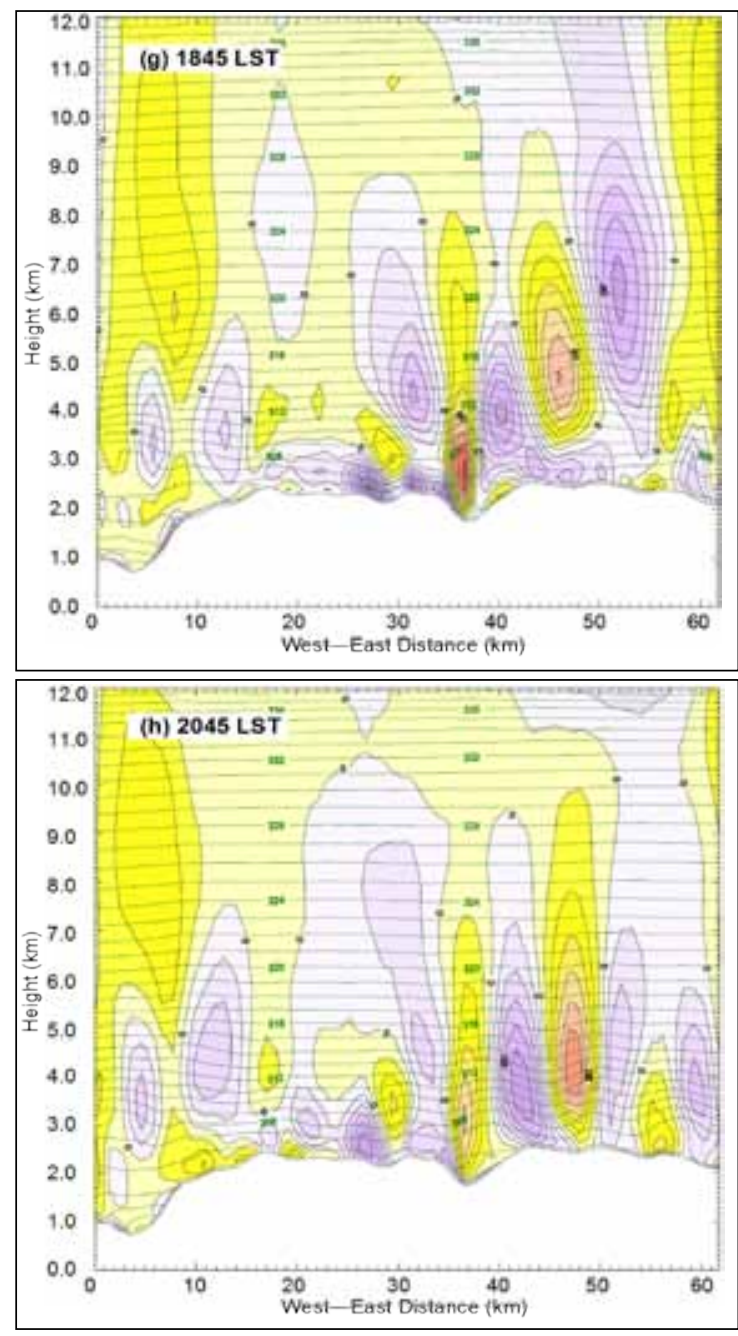

of potential temperature contours strongly suggest that trapped atmospheric undulations [Durran, 1990] prevails over the eastern part of the mountain range up to the height of $8 \mathrm{~km}$ AMSL. The elevated areas left to the mountain pass may remain under the influence of weak and shallow subsidence whereas the eastern areas from the pass alternately receive strong up- and downdrafts. These up- and downdrafts appears to be effective up to the height of $8 \mathrm{~km}$ AMSL. The speed of updrafts appears to vary from about $20 \mathrm{~cm} \mathrm{~s}^{-1}$ to more than $160 \mathrm{~cm} \mathrm{~s}^{-1}$.

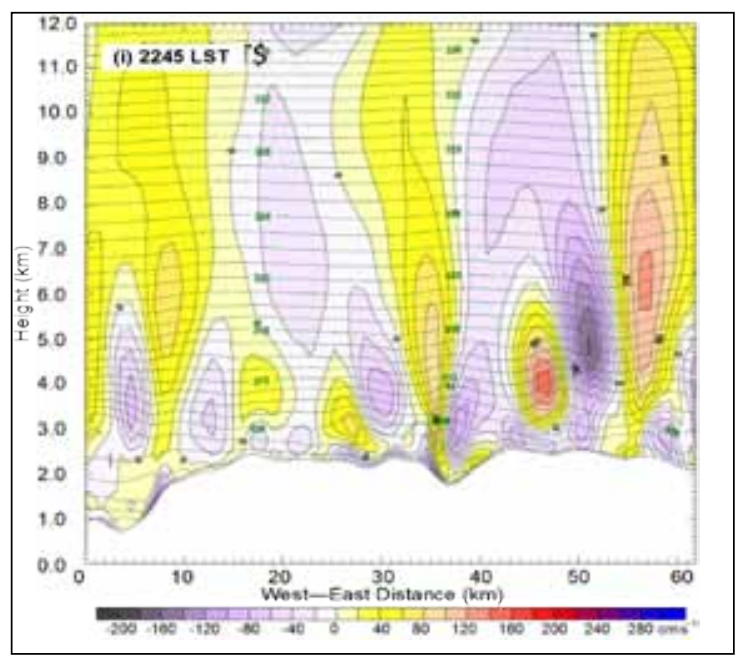

Figure 2. Cross-sectional distribution of vertical wind velocity $\left(\mathrm{cm} \mathrm{s}^{-1}\right)$ along the ridgeline of Tufan Dada mountain range superimposed with potential temperature contours at the interval of $1^{\circ} \mathrm{K}$ (see Figure 1 for line $\mathrm{A}-\mathrm{B}$ along which the cross section is drawn).

Likewise, the downdraft speeds vary from 20 $\mathrm{cm} \mathrm{s}^{-1}$ to $200 \mathrm{~cm} \mathrm{~s}^{-1}$. Thus, the eastern part of the Tufan Dada may remain highly turbulent during the morning hours. Over the mountain pass (see Figure 2a) the updrafts with maximum velocity close to $160 \mathrm{~cm} \mathrm{~s}^{-1}$ may prevail up to 2 $\mathrm{km}$ above the surface.

As morning progresses, the basic distribution patterns of up- and downdrafts appear to be continued with few scattered anomalies like maximum intensity of updraft reaches to about $200 \mathrm{~cm} \mathrm{~s}^{-1}$. However, by late morning, significant changes are apparent. For example, the downdrafts that prevailed above $3 \mathrm{~km}$ AMSL over the western lowlands during the early morning times come down to the surface level and the directional wind shear can be expected over the eastern part of the range (see Figure 2c). Close to the noontime, the 
upper troposphere over the western lowlands develops significant updrafts (see Figure 2d). Likewise, the updrafts over the mountain pass strengthen but the up- and downdrafts over the western part of the mountain range persists as in the morning times.

In the afternoon, examining the plots for every 15 minutes interval it is seen that around 1400 LST (not shown), atmospheric undulations (trapped mountain waves) suddenly onsets from the western end of the Tufan Dada range and propagates horizontally towards the east that can be learnt by comparing Figures $2 \mathrm{~d}$ and Figure 2e. These up- and downdrafts may extend up to the height of troposphere but remain highly effective up to the height of $6 \mathrm{~km}$ AMSL. Contrary to the morning and noontime, in the afternoon times the up- and downdrafts strengthen over the western part of the Tufan Dada mountain range whereas they are weakened over the eastern part (see Figure $2 \mathrm{~d}$ and $2 \mathrm{e}$ ). During the period, there is switching from downdraft to updraft over the mountain pass areas. During the late afternoon times, the mountain pass area holds strongest updraft in the whole $60 \mathrm{~km}$ long mountain range. The updraft speed may exceed $180 \mathrm{~cm} \mathrm{~s}^{-1}$ during the period and may extend beyond tropospheric height with the speed of $40 \mathrm{~cm} \mathrm{~s}^{-1}$ (see Figure 2f).

Beyond the late afternoon, the pronounced afternoon time vertical motions over the Tufan Dada begin to subside significantly (see Figure $2 \mathrm{~g}$ ) and at the dusk the lower troposphere (lowest $4 \mathrm{~km}$ ) holds feeble downdrafts except right over the mountain pass where the significant updrafts still prevails. Beyond late evening, the up- and downdrafts gradually activate over the whole mountain range to resume nearly the same early morning situation next day described earlier (see Figures 2h-i and Figure 2a).

It, thus, appears that there is strong diurnal periodicity in the distribution of vertical motions over the Tufan Dada mountain range during the early spring season. Furthermore, the atmospheric undulations over the Tufan Danda mountain range are trapped undulations and largely confined within the lowest troposphere below $4 \mathrm{~km}$ AMSL. It is important to note that as the afternoon time up- and downdrafts are appreciably high and may extend beyond tropospheric height, they can play significant role in transporting low level pollutants up into the upper atmosphere and vice versa.

As discussed earlier, this is the region where different regional winds from beyond the boarder interact in complicated manner and build-up pronounced daytime upvalley wind system towards the high Himalayas via Tufan Dada mountain range [Regmi and Maharjan, 2015], the regional wind may bring regional pollutants over Tufan Dada mountain range from corresponding downwind areas. Although, it cannot be overly stressed because the present study is yet to be complemented with atmospheric transport modeling and observations, it is likely that Tufan Dada mountain range might have playing significant role in pumping up the regional pollutants up into the upper troposphere.

\section{Conclusions}

High resolution WRF simulation was performed to study the characteristic behavior and diurnal periodicity of vertical wind over the Tufan Dada mountain range in the Far-Western region of Nepal during the early spring season. 
The prevalence of significantly high up- and downdrafts activities often extending up to the upper part of the troposphere over the mountain range most of the time suggests appreciable coupling of lower and upper tropospheric air masses. Orographically induced mountain waves over the Tufan Dada mountain range are likely to add further momentum in coupling the upper and lower tropospheric air masses. The fair weather updraft and downdraft speed over the mountain range during the early spring season may reach more than $180 \mathrm{~cm} \mathrm{~s}^{-1}$ and 200 $\mathrm{cm} \mathrm{s}^{-1}$, respectively. Thus, we can expect the excessively high vertical motions in convective periods over the Tufan Dada mountain range. The appearance of appreciable up- and downdrafts at about $12 \mathrm{~km}$ AMSL indicate high possibilities of coupling and mass exchange in between stratosphere and troposphere over the Dadeldhura region as well. The study has shown that Dadeldhura and, particularly, the Tufan Dada mountain range could be one of the potential areas to assess the possibility of stratospheric ozone intrusion to the troposphere in Nepal. This study has opened the new window to access the possibility of stratospheric ozone intrusion to the troposphere. However, as the present study lacks its verifications with observation data, further investigation complemented with observation are expected to be assertive in its findings although the strengthen of present days advanced numerical modeling such as WRF cannot be undermined. Past experiences of successful reconstructions of atmospheric transport processes in different parts of the extreme Himalayan complex terrains [e.g., Regmi et al., 2003; Kitada and Regmi, 2003; Maharjan, 2013; Regmi, 2013], suggest that the predictions made with WRF over Tufan Dada mountain range are not much deviated from the real situations.

\section{Acknowledgments}

This study was possible from the research facilities developed at NARERL, Central Department of Physics, Tribhuvan University, Nepal through the Research Grant, 2011 awarded by the University Grant Commission, Nepal under its Institutional Grant Research Project scheme. Thus, authors would like to acknowledge the University Grant Commission Nepal. Editor N. P. Chapagain thanks two anonymous referees for their assistant in evaluating this paper.

\section{References}

Acharya. S., S. Neupane, R. Shrestha, C. Chapagain, P. Acharya, S. Maharjan and R. Regmi (2014), Early monsoon time local flow characteristics over Hetauda valley and its implications, Journal of Institute of Science and Technology, vol. 19, No. 1, 109-117.

Brun J., P. Shrestha , A.P. Barros, (2011) Mapping Aerosol Intrusion in Himalayan Valleys Using the Moderate Resolution Imaging Spectroradiometer (MODIS) and CloudAerosol Lidar and Infrared Pathfinder Satellite Observation (CALIPSO). Atmos. Env., doi:10.1016/ j.atmosenv.2011.08.026

Cifelli, R., and S. A. Rutledge (1994), Vertical motion structure in maritime continent mesoscale convective systems: Results from a $50-\mathrm{MHz}$ profiler, J. Atmos. Sci., 51, 2631-2652.

Dhaka, S. K., R. K. Choudhary, S. Malik, Y. Shibagaki, M. D. Yamanaka, and S. Fukao (2002), Observable signatures of a convectively generated wave field over the tropics using Indian MST radar at Gadanki (13.5_N, 79.2_E), Geophys. Res. Lett., 29(18), 1872, doi:10.1029/2002GL014745

Durran, D. R., 1990: Mountain waves and downslope winds, Meteorological Monographs, vol. 23, No. 45 , pages 59-81. 
Ecklund, W. L., K. S. Gage, A. C. Riddle (1981), Gravity wave activity in vertical winds observed by the Poker flat MST radar. Geophys. Res. Lett., 8, 285-288.

Ecklund, W. L., K. S. Gage, B. B. Balsley, R. G. Strauch, and J. L. Green (1982), Vertical wind variability observed by the VHF radar in the lee of Colorado Rockies, Mon. Weather Rev., 110, 1451- 1457.

Fleagle, R. G. (1959). On the mechanism of largescale vertical motion.Jour. of Appl. Meteorology, Vol.15, No.3, pp 249-258.

Gage, K. S. (1990), Radar observations of the free atmosphere:Structure and dynamics, in Radar in Meteorology, edited by D. Atlas, 534-565 pp., Am. Meteorol. Soc., Boston, Mass.

Gage, K. S., B. B. Balsley, W. L. Ecklund, D. A. Carter, and J. R. McAfee (1991), Wind profilerrelated research in the tropical Pacific, $J$. Geophys. Res., 96, 3209-3220.

Gage, K. S., J. R. McAfee, D. A. Carter, W. L. Ecklund, A. C. Riddle, G. C. Reid, and B. B. Balsley, 1991: Long-term mean vertical motion over the tropical Pacific, Wind-profiling Doppler radar measurements. Science, 254, 1771-1773.

Jagannadha Rao, V. V. M., D. N. Rao, M. V. Ratnam, K. Mohan, and S.V. B. Rao (2003), Mean vertical velocities measured by Indian MST radar and comparison with indirectly computed values, $J$. Appl. Meteorol., 42, 541-552.

Maharjan, S. (2014b), Intrusion of moisture over the Kathmandu valley from southern plain, The Himalayan Physics, Vol.5, No.5, Nov 2014.

Maharjan, S. (2014a), Springtime meteorology of the Damauli valley, Nepal: Implications for climatic comfort and environmental hygiene, Journal of Institute of Science and Technology, vol. 19, No. 2, 24-29.

Nastrom, G. D., and T. E. VanZandt (1994), Mean vertical motions seen by radar wind profilers, $J$. Appl. Meteorol., 33, 984-995.
Panday, A. K., R. Prinn (2009), Diurnal cycle of air pollution in the Kathmandu Valley, Nepal: Observations, Journal of Geophysical Research: Atmospheres (1984-2012), Volume 114, Issue D9, 16 May 2009. DOI: 10.1029/2008JD009777.

Piani, C., and D. R. Durran (2001), A numerical study of stratospheric gravity waves triggered by squall lines observed during the TOGA COARE and COPT-81 experiments, J. Atmos. Sci., 58, 3702-3723.

Ram P. Regmi, T. Kitada, and G. Kurata, (2003), Numerical Simulation of Late Wintertime Local Flows in Kathmandu Valley, Nepal: Implication for Air Pollution Transport, J. Appl. Meteor., 42, 389-403.

Regmi, R. P. (2013a), Springtime windstorm in the Kathmandu valley and its predictability, Journal of Institute of Science and Technology, vol. 18, No. 2, 28-36.

Regmi, R. P. (2013b), Preliminary Study on the state of pre-monsoon time climatic comfort over the Chitwan valley, Nepal. The Himalayan Physics, Vol., 4, 59-69.

Regmi, R. P. (2014b), Aviation hazards in the sky over Thada as revealed by meso-scale meteorological modeling, Journal of Institute of Science and Technology, vol. 19, No. 2, 65-70.

Regmi, R. P. (2014a), Aviation hazards over the Jomsom Airport of Nepal as revealed by numerical simulation of local flows, Journal of Institute of Science and Technology, vol. 19, No. 1, 111-120.

Regmi, R. P. and S. Maharjan (2013), Wind Energy Potential of Middle Hills of Nepal Himalaya, World Wind Energy International Quarterly Bulletin, ISSUE 1, March.

Regmi, R. P. and S. Maharjan (2015), Evolution of Late Wintertime Thermally Driven Local flows and Temperature Fields over Far-Western Nepal, Journal of University Grant Commission, Nepal (communicated). 
Röttger, J. (1980), Structure and dynamics of the stratosphere and mesosphere revealed by the VHF radar investigations, Pure Appl. Geophys., 118, 494-527

S. Maharjan and Ram P. Regmi (2013): Mechanism of intrusion and channeling of regional air mass over Kathmandu valley, Journal of Institute of Science and Technology, vol. 19, No. 1, 77-83.

S. Maharjan and Ram P. Regmi (2014), Grid based temperature and relative humidity distribution map of the Kathmandu valley, Journal of Institute of Science and Technology, vol. 19, No. 1,7-13.

Shrestha P., A.P. Barros (2010), Joint spatial variability of aerosol, clouds and rainfall in the Himalayas from satellite data, Atmos. Chem. Phys., 10, 8305-8317, doi:10.5194/acp-10-83052010.

Shrestha P., Barros A.P., Khlystov A. (2010), Chemical composition and aerosol size distribution of the middle mountain range in the Nepal Himalayas during the 2009 pre-monsoon season, Atmos. Chem. and Phys. -10, 1160511621, doi:10.5194/acp-10-11605-2010.
Skamarock, W. C., and Coauthors, (2008), A description of the Advanced Research WRF version 3. NCAR Tech. Tep. TN-475+STR, 113 pp.

Kitada, T. and Ram P. Regmi, 2003: Dynamics of Air Pollution Transport in Late Wintertime over Kathmandu Valley, Nepal: As Revealed with Numerical Simulation, J. Appl. Meteor., 42, 1770-1798.

Uma, K. N., and T. N. Rao (2009), Diurnal variation in vertical air motion over a tropical station, Gadanki (13.5_N, 79.2_E), and its effect on the estimation of mean vertical air motion, J. Geophys. Res., 114, D20106, doi:10.1029/2009JD012560.

Wheeler, M., G. N. Kiladis, and P. J. Webster (2000), Largescale dynamical fields associated with convectively coupled equatorial waves, $J$. Atmos. Sci, 57, 613-640.

Yamamoto, M. K., N. Nishi, T. Horinouchi, M. Niwano, and S. Fukao (2007), Vertical wind observation in the tropical upper troposphere by VHF wind profiler: A case study, Radio Sci., 42, RS3005, doi:10.1029/2006RS003538. 